Revista de Metalurgia 50(2)

Abril-Junio 2014, e014

ISSN-L: 0034-8570

doi: http://dx.doi.org/10.3989/revmetalm.014

\title{
Estudio de la influencia microbiológica en la corrosión de latones (UNS C68700, UNS C443) y acero inoxidable AISI 316
}

\author{
Mauricio Ohanian $^{\mathrm{a},}$, Verónica Díaz ${ }^{\mathrm{a}}$, Mariana Corengia ${ }^{\mathrm{a}}$, Paola Russi ${ }^{\mathrm{a}}$, \\ María Julia Pianzzola ${ }^{b}$, Rodolfo Javier Menes ${ }^{b}$ \\ ${ }^{a}$ Grupo de Ingeniería Electroquímica, Instituto de Ingeniería Química, Facultad de Ingeniería, Universidad de la República, Julio \\ Herrera y Reissig 565, Montevideo, Uruguay \\ ${ }^{\mathrm{b}}$ Cátedra de Microbiología, Departamento de Biociencias, Facultad de Química y Unidad Asociada de Facultad de Ciencias, \\ Universidad de la República, Av. General Flores 2124, Montevideo, Uruguay \\ Autor para la correspondencia: mohanian@fing.edu.uy
}

Enviado: 10 Mayo 2013; Aceptado: 7 Marzo 2014

\begin{abstract}
RESUMEN: Los microorganismos influyen de manera significativa en el proceso corrosivo y generan condiciones que afectan la velocidad y/o el mecanismo de deterioro. Su presencia se manifiesta por la formación de bio-películas: conglomerados de bacterias y polímeros extracelulares. Dichas bio-películas afectan la durabilidad del material, la velocidad de flujo y la transferencia de calor. En el presente trabajo se evalúa el crecimiento de microorganismos heterótrofos aerobios, heterótrofos anaerobios y bacterias sulfato-reductoras sobre latón aluminio (UNS C68700), latón almirantazgo (UNS C443) y acero inoxidable AISI 316. Asimismo, se estudia la influencia del crecimiento de la bio-película sobre el comportamiento corrosivo mediante técnicas electroquímicas: curvas de polarización y espectroscopia de impedancia electroquímica. Las exposiciones se realizan en la Bahía de Montevideo, estuario del Río de la Plata (Uruguay). A partir de los resultados obtenidos se establecen hipótesis acerca del mecanismo asociado, a la vez que se discuten criterios de selección de materiales en las condiciones particulares de exposición. Aunque el acero inoxidable AISI 316 muestra una velocidad media de corrosión inferior a los otros materiales ensayados, presenta una tendencia a la generación de fenómenos de deterioro localizado.
\end{abstract}

PALABRAS CLAVE: AISI 316; Bacterias sulfato reductoras; Biocorrosión; Latón almirantazgo; Latón aluminio; Técnicas electroquímicas

Citation / Cómo citar este artículo: Ohanian, M., Díaz, V., Corengia, M., Russi, P., Pianzzola, M.J., Menes, R.J. (2014) "Estudio de la influencia microbiológica en la corrosión de latones (UNS C68700, UNS C443) y acero inoxidable AISI 316". Rev. Metal. 50(2): e014. doi: http://dx.doi.org/10.3989/revmetalm.014.

ABSTRACT: Microbiologically influenced corrosion evaluation on brass (UNS C68700, UNS C443) and AISI 316 stainless steel. Microorganisms may play an important role in the corrosion process and generate conditions which affect the rate and/or the mechanism of deterioration. They become visible by the formation of biofilms: clusters of microorganisms and extracellular polymers. These biofilms affect not only the durability of the material, but also reduce the heat transfer. The present work studied the growth of aerobic and anaerobic heterotrophic microorganisms and sulfate reducing bacteria on aluminum brass (UNS C68700), admiralty brass (UNS C443) and stainless steel AISI 316 in exposure experiments held in the Bay of Montevideo (Uruguay). The influence of the biofilm growth on the corrosion behavior was studied by electrochemical techniques: polarization curves and Electrochemical Impedance Spectroscopy (EIS). The selection of the most suitable material for the exposure conditions is discussed and hypotheses of the corrosion mechanism are presented. Although stainless steel AISI 316 presented the lowest corrosion rate it showed localized deterioration.

KEYWORDS: AISI 316; Admiralty brass; Aluminum brass; Electrochemical techniques; MIC; Sulfate reducing bacteria

Copyright: $(\mathbb{C} 2014$ CSIC. This is an open-access article distributed under the terms of the Creative Commons AttributionNon Commercial (by-nc) Spain 3.0 License. 


\section{INTRODUCCIÓN}

La Central Batlle y Ordoñez (Montevideo, Uruguay) es una central térmica de producción de energía eléctrica por ciclo de vapor Rankine con sobrecalentamiento (Faires y Simmang, 1982). Para la refrigeración del ciclo se utiliza el agua de la bahía de Montevideo (estuario del Río de la Plata). La composición y propiedades fisicoquímicas del agua son altamente variables y dependen de la estacionalidad y del régimen de lluvia (IMM Servicio Laboratorio de Calidad Ambiental, 2011). El circuito de enfriamiento es abierto y de un pase: el agua se toma y posteriormente se descarga a mayor temperatura. Como tratamiento del agua se realiza un filtrado y se retienen los sólidos de gran tamaño, pero no se realiza ningún tipo de tratamiento químico, como es habitual encontrar en este tipo de sistema (Cristiani, 2005). En toda la extensión del sistema de enfriamiento se observa la presencia de películas sobre las superficies, de carácter viscoso y resbaladizo. Análisis preliminares demuestran que esta película es un conglomerado de organismos microscópicos y polímeros extracelulares. La caracterización microbiológica del mismo muestra variedad de hongos unicelulares, bacterias aerobias y anaerobias (Russi et al., 2012). Asimismo se encuentran macro-organismos de los filos: moluscos, artrópodos, anélidos, etc. (Figs. 1 y 2). Como consecuencia de la acumulación de organismos en las paredes del sistema, existe una reducción de la sección de flujo y un aumento en la rugosidad superficial, lo que aumenta las pérdidas de carga en el circuito y disminuye el caudal circulante. La disminución del caudal genera una disminución del coeficiente de transferencia de calor por convección,

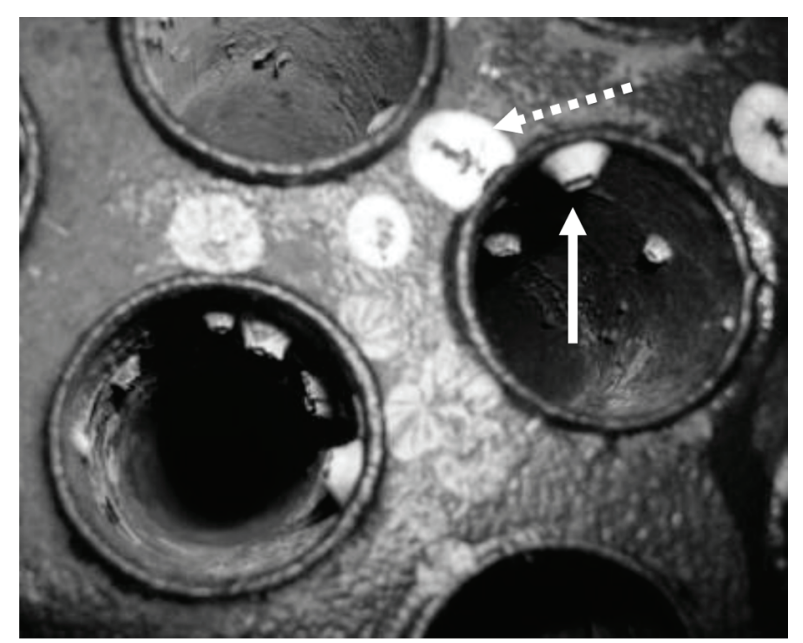

Figura 1. Aspecto de una placa de tubos de condensador durante operación de mantenimiento. Se observa crecimiento de moluscos dentro de los tubos (indicada con flecha) y las marcas originadas en la placa por la eliminación de los mismos (marcas ovales blancas, flecha segmentada). que se suma a la interposición de una capa de organismos y polímeros extracelulares (lo cual constituye una resistencia adicional a la transferencia energética). La disminución de transferencia de calor disminuye la eficiencia de los condensadores y por tanto genera una pérdida de eficiencia de la unidad de producción de energía, la cual se ve acentuada debido a los paros no previstos para realización de limpiezas en el sistema de refrigeración.

La denominación de corrosión influenciada por actividad microbiológica MIC (Microbiologically Influenced Corrosion) es utilizada para designar los procesos corrosivos donde los microorganismos son capaces de iniciar o acelerar la reacción electroquímica o cambiar el mecanismo de reacción. En términos más generales, la bio-incrustación (biofouling) se aplica a crecimientos tanto micro como macro biológicos sobre superficies, los cuales pueden tener tanto efectos acelerantes como inhibitorios de la corrosión (de Romero et al., 2003; Gómez de Saravia et al., 2003; Little y Lee, 2007). La formación de la bio-película puede ocurrir en minutos o en horas, de acuerdo al ambiente donde esté inmerso el metal. La primera etapa en la formación, es la unión electrostástica de sustancias orgánicas e inorgánicas al metal, seguida de una etapa en la que se produce la adhesión de microorganismos planctónicos por medio de exopolisacáridos, que en esta etapa se les conoce como microorganismos sésiles, por oposición a su estado planctónico. Cuando los microorganismos se adhieren a la interfase y forman la bio-película, se genera un gradiente de nutrientes y metabolitos. Estos microorganismos requieren de una fuente de carbono (y otros nutrientes), una fuente de energía (que actúa como dador de electrones) y de un receptor de electrones para su crecimiento.

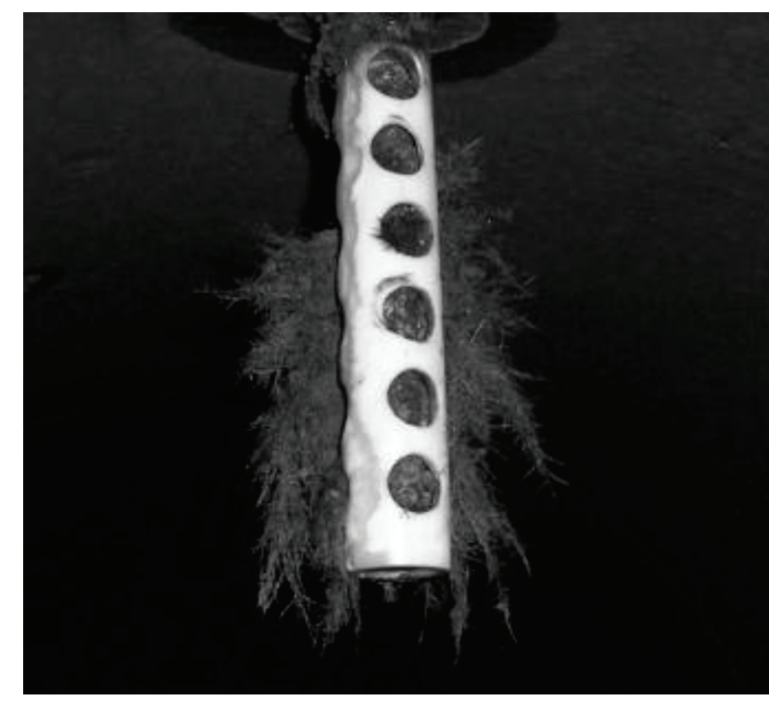

Figura 2. Colonización por anélidos de portaelectrodo de sistema de protección catódica en el conducto de entrada del condensador. 
En la mayoría de los procesos MIC, la morfología del ataque corrosivo es localizada, pudiéndose encontrar picado y dealeado. Por otra parte, puede generarse un aumento de la influencia de los mecanismos de erosión, efecto galvánico, corrosión bajo tensión y fragilización por hidrógeno. Existen antecedentes de MIC en todos los metales y aleaciones utilizadas en ingeniería, en medios tan diversos como: agua de mar, agua destilada, petróleo y derivados, plasma humano, productos alimenticios, fluidos químicos, etc. Hay autores que sugieren que el $50 \%$ de los costes de corrosión son ocasionados por MIC, siendo las industrias más afectadas la producción de energía, transporte, almacenamiento de combustible y distribución de agua (Videla y Salvarezza, 1984). Debido a la complejidad de los fenómenos involucrados (metalúrgicos, microbiológicos, electroquímicos, etc.), el efecto causado por los microorganismos sobre el deterioro de los materiales no está completamente dilucidado (Stott, 2010).

En el presente trabajo se exponen durante 15 días en la bahía de Montevideo, tres materiales diferentes: latón aluminio (UNS C68700), latón almirantazgo (UNS C443) y acero inoxidable AISI 316 (Roberge, 1999). El objetivo del trabajo es conocer la influencia del material sobre el desarrollo de la microbiota y estudiar la influencia de esta última sobre el proceso corrosivo.

\section{MATERIALES Y MÉTODOS}

\subsection{Construcción de probetas}

Las probetas de ensayo se construyeron con trozos de tubos de diámetro $254 \mathrm{~cm}$ y $1 \mathrm{~cm}$ de largo. Dichos trozos se perforaron para realizar contacto eléctrico y se embebieron en resina epoxi. El borde expuesto se lijó a granulometría $200 \mu \mathrm{m}$. Las probetas se expusieron durante 15 días en la bahía de Montevideo, a una profundidad de inmersión de $1 \mathrm{~m}$. Para cada material se utilizaron dos probetas, una destinada a estudios microbiológicos y otra, a estudios electroquímicos. Se trabajó con tres materiales diferentes: latón almirantazgo UNS C443 (AT), latón aluminio UNS C68700 (AL) y acero inoxidable AISI 316.

\subsection{Muestreo y cuantificación}

La bio-película de la superficie expuesta se recogió con hisopo estéril (ver Figura 3) y se suspendió en medio anaerobio API-RST (Tanner, 1989). Se realizaron diluciones sucesivas en solución anaerobia de $0,01 \%$ ácido ascórbico, $0,01 \%$ clorhidrato de cisteína y $0,01 \%$ extracto de levadura y $\mathrm{pH} 7,0$. Para la estimación del número de Bacterias Sulfato Reductoras (BSR) se utilizó el método de dilución hasta extinción en medio líquido: se inocularon
$0,1 \mathrm{ml}$ de las diferentes diluciones en $9 \mathrm{ml}$ de medio API-RST (en viales anaerobios preparados con atmósfera de nitrógeno). Los viales se incubaron a $30{ }^{\circ} \mathrm{C}$ durante 20 días y se consideraron positivos aquellos que presentaron aparición de precipitado negro. El recuento de heterótrofos anaerobios se realizó por siembra incorporada de $0,1 \mathrm{ml}$ de las diferentes diluciones en Reinforced Clostridial agar $\left(\mathrm{RCM}\right.$ agar, Oxoid ${ }^{\circledR}$ ) y se incubaron a $30^{\circ} \mathrm{C}$, durante 5 días en recipiente con generador anaerobio (Genbag anaer, bioMérieux ${ }^{\circledR}$ ). El recuento de heterótrofos aerobios se realizó por siembra en superficie de $0,1 \mathrm{ml}$ de las diferentes diluciones en Agar tripticasa soja (TSA, Oxoid ${ }^{\circledR}$ ) y se incubaron a $30{ }^{\circ} \mathrm{C}$ durante 5 días.

\subsection{Análisis electroquímico}

La caracterización electroquímica de la superficie se realizó a $20^{\circ} \mathrm{C}$. Se utilizó una celda de vidrio de $1000 \mathrm{ml}$ de capacidad, Radiometer ${ }^{\circledR} \mathrm{CNC}$ construida de acuerdo a la normativa ASTM G3-13 (2013). La celda dispone de tres electrodos: electrodo de trabajo (material en estudio), contraelectrodo de platino platinizado y electrodo de referencia de calomel saturado (SCE, Saturated Calomel Electrode, $+0,242 \mathrm{~V}$ respecto al electrodo normal de hidrógeno). El electrolito de trabajo fue sulfato de sodio $0,1 \mathrm{M}$ a $\mathrm{pH}$ 7. La aireación de la solución se realizó en forma natural por la interfase aire/electrolito. Se empleó una interfase electroquímica Radiometer ${ }^{\circledR}$ PGZ 301 acoplada a un ordenador personal.

Se realizaron estudios de voltamperometría, en los cuales se impuso una perturbación de potencial entre el electrodo de trabajo y el contra-electrodo, registrándose la densidad de corriente circulante entre ellos. La perturbación de potencial fue de tipo lineal en el tiempo, con velocidad de variación de $5 \mathrm{mVs}^{-1}$. Para cada material se determinaron, en ensayos preliminares, los intervalos de potencial.

Las experiencias de EIS (Electrochemical Impedance Spectroscopy) se realizaron al potencial de corrosión, previa estabilización, tomando como criterio de estabilidad una variación menor a

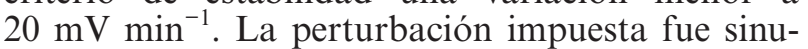
soidal con una amplitud de $10 \mathrm{mV}$; el intervalo de frecuencias utilizado fue $1000 \mathrm{~Hz}$ a $0,1 \mathrm{~Hz}$ y se registraron cinco determinaciones por década. Los resultados se ajustaron mediante el programa Zview ${ }^{\circledR}$. Los modelos de ajuste propuestos se muestran en las Figuras 4 y 5 . El modelo de la Figura 4 presenta dos constantes de tiempo. En el mismo se representa la interfase electroquímica a través de la resistencia óhmica de la solución (Rs), en serie con un circuito paralelo con 2 ramas: una resistencia a la transferencia de carga (R1) en serie con un elemento de Warburg asociado a un proceso de difusión en capa finita (W1) y un elemento capacitivo de fase 

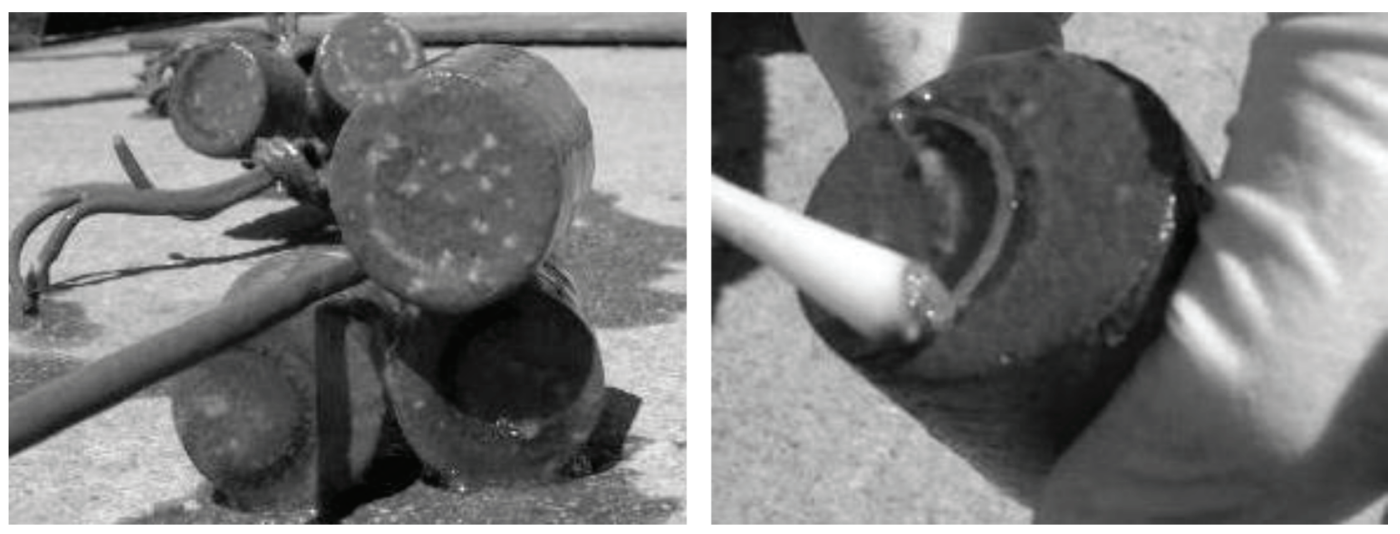

Figura 3. Probetas construidas con trozos de tubo metálico incluidos en resina epoxi, después de la exposición durante 15 días en la Bahía de Montevideo. A la derecha se muestra la operación para el muestreo de la bio-película.

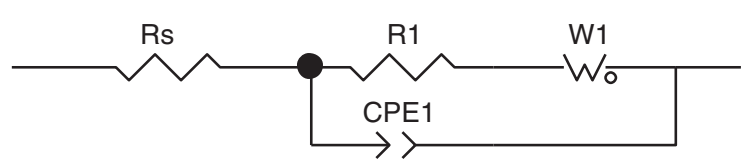

FIgURA 4. Modelo eléctrico utilizado para ajuste de resultados EIS. RS: resistencia óhmica de la solución, R1: resistencia a la transferencia de carga, W1: elemento de Warburg y

CPE1: elemento capacitivo de fase constante.

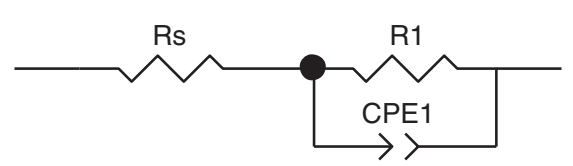

FIGURA 5. Modelo eléctrico utilizado para ajuste de resultados EIS. RS: resistencia óhmica de la solución, R1: resistencia a la transferencia de carga y CPE1: elemento capacitivo de fase constante.

constante asociado al comportamiento capacitivo de la doble capa electroquímica (CPE1) (Orazem y Tribollet, 2008a). El modelo de la Figura 5 presenta una única constante de tiempo, diferenciándose del modelo anterior por no presentar el elemento difusivo.

La impedancia del elemento de Warburg puede expresarse como se indica en la ecuación (1) (Orazem y Tribollet, 2008b):

$$
Z_{W}=W s R\left[\frac{\tanh (j W s T \omega)^{W s P}}{(j W s T \omega)^{W s P}}\right]
$$

donde el parámetro WsT puede relacionarse con el espesor de difusión efectivo $(L)$ y el coeficiente de difusión $(D)$ mediante la expresión:

$$
W s T=\frac{L^{2}}{D}
$$

La impedancia correspondiente al elemento de fase constante (CPE) se expresa como:

$$
Z_{C P E}=\frac{1}{Y_{1}(j \omega)^{\alpha}}
$$

Los ensayos EIS se llevaron a cabo para una muestra testigo sin exponer y para la muestra al cabo de 15 días de exposición en campo.

\section{RESULTADOS Y DISCUSION}

\subsection{Cuantificación microbiológica}

Los resultados de los recuentos realizados se muestran en la Tabla 1. El número de heterótrofos aerobios es similar en las tres muestras, lo que indica que el tipo de aleación no influye de forma drástica en el número de microorganismos sésiles del metal. Sin embargo se observan diferencias en los valores de recuentos de heterótrofos anaerobios: AT presenta un número de anaerobios cien veces inferior a los obtenidos para AL y AISI 316, lo cual sugiere que AT presenta una diferente composición y estructura de la bio-película. Respecto a las BSR, si bien se observan valores elevados de recuento para las tres muestras, AISI 316 es la que presenta el mayor valor. La presencia de BSR sésiles en la superficie del metal tiene como resultado una velocidad de corrosión mayor que la causada por las bacterias planctónicas (Liu et al., 2000). Si bien no se ha establecido hasta el momento cuál es la mínima concentración de bacterias planctónicas necesarias para causar problemas de corrosión, algunos autores sugieren que valores superiores a $10^{4} \mathrm{~cm}^{-3}$ de BSR podrían causar corrosión microbiológica (Videla, 1996).

\subsection{Caracterización electroquímica}

En la Figura 6 se representan las curvas de polarización (curvas de Tafel) de los materiales sin exponer y las obtenidas después de 15 días de exposición. 
TABLA 1. Recuentos de heterótrofos aerobios, anaerobios y bacterias sulfato reductoras (BSR) en muestras de latón almirantazgo UNS C443 (AT), acero inoxidable AISI 316 y latón aluminio UNS C68700 (AL), a los 15 días de exposición

\begin{tabular}{|c|c|c|c|}
\hline Material & $\begin{array}{c}\text { Heterótrofos aerobios } \\
\left(\mathrm{UFC} \mathrm{cm}^{-2}\right)\end{array}$ & 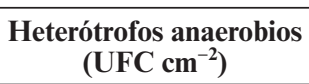 & $\begin{array}{c}\text { BSR } \\
\left.\text { (células cm } \text { cm }^{-2}\right)\end{array}$ \\
\hline AT & $1,5 \times 10^{5}$ & $2,8 \times 10^{3}$ & $10^{4}$ \\
\hline AISI 316 & $9,1 \times 10^{5}$ & $2,3 \times 10^{5}$ & $10^{5}$ \\
\hline $\mathrm{AL}$ & $6,1 \times 10^{5}$ & $1,3 \times 10^{5}$ & $10^{3}$ \\
\hline
\end{tabular}

${ }^{a}$ UFC: unidades formadoras de colonias.
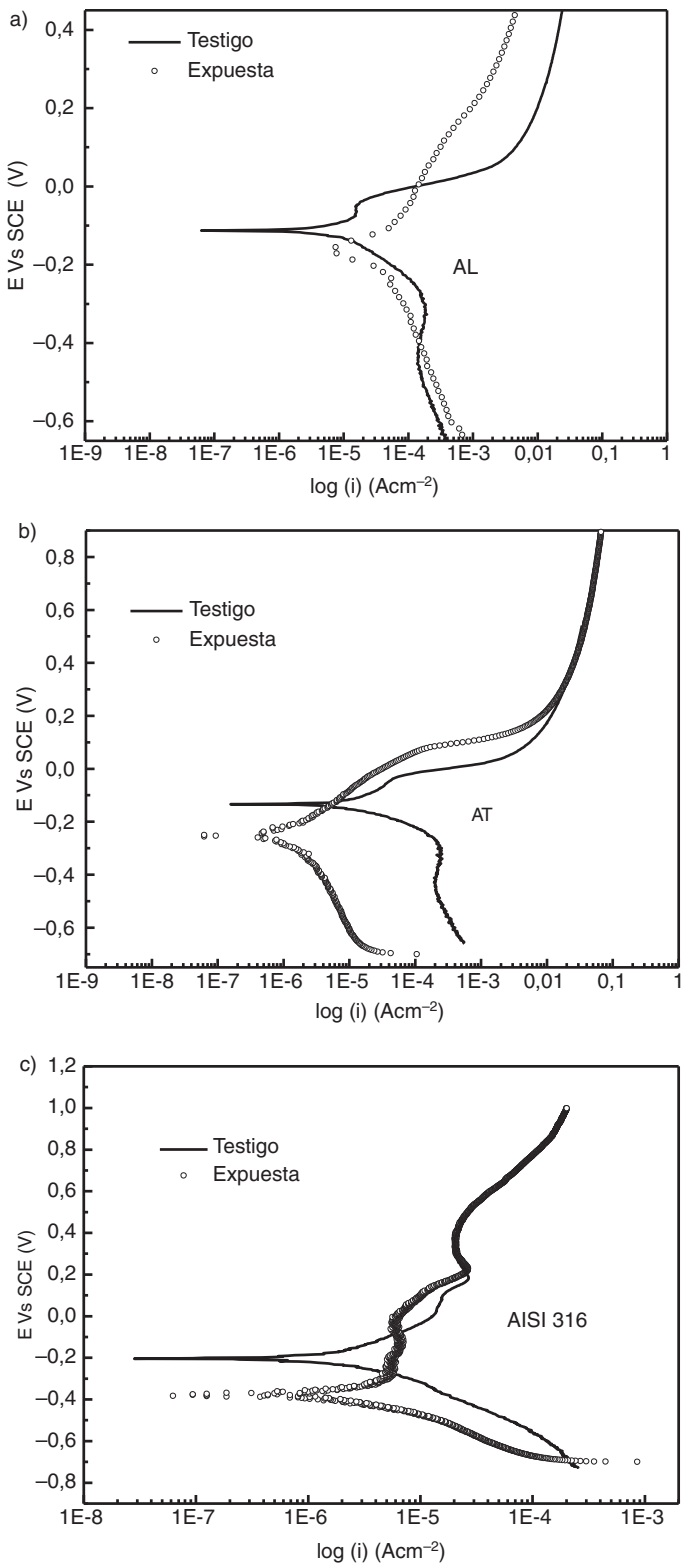

Figura 6. Curvas de Tafel para los tres materiales expuestos en la Bahía de Montevideo: a) latón aluminio UNS C68700

(AL); b) latón almirantazgo UNS C443 (AT) y c) acero inoxidable AISI 316 (AISI 316).
A partir de estas curvas se determinaron los parámetros electroquímicos: potencial de corrosión (Ecorr), pendiente anódica y catódica (ba y bc). Se determinó también la resistencia a la polarización lineal $(\mathrm{Rp}$, a partir del gráfico potencial vs. densidad de corriente) y la densidad de corriente de corrosión (icorr) calculada mediante el método de SternGeary (Cottis, 2010). Los parámetros electroquímicos se muestran en la Tabla 2.

Para todos los materiales se puede observar que las probetas expuestas tienen un menor potencial de corrosión que las utilizadas como testigos: una reducción aproximada de $0,06 \mathrm{~V}$ en los latones y de $0,17 \mathrm{~V}$ en el acero inoxidable.

Para AISI 316 y AT se observa una marcada disminución de la densidad de corriente catódica. Sin embargo, para dichos materiales no está afectada significativamente la respuesta asociada a la rama anódica en altos sobrepotenciales. Para AL se observa un comportamiento diferente: no disminuye la respuesta catódica y se registran densidades de corriente anódicas menores en la muestra expuesta. En todas probetas expuestas existe un aumento de la pendiente de Tafel catódica.

Para AISI 316 se observa un marcado aumento de la pendiente anódica a potenciales muy cercanos al de corrosión y el fenómeno se acompaña con una alta dispersión de los resultados en el entorno de potencial antes mencionado. Este comportamiento podría indicar la generación de procesos localizados en la superficie. Cabe señalar que la localización del proceso no se evidencia en los valores obtenidos de la velocidad de corrosión por tratarse ésta de una velocidad media asociada a toda la superficie expuesta. El fenómeno de picado sobre AISI 316, ha sido anteriormente puesto de manifiesto en condiciones de servicio en el ambiente considerado (Ohanian et al., 2011).

En la Tabla 2 se observa que las velocidades medias de corrosión calculadas para AL y AISI 316 son mayores para las probetas expuestas que para los testigos. Para AT el valor de velocidad calculado es levemente inferior en la muestra expuesta, siendo el único material en el que el valor de la pendiente anódica de la probeta expuesta es menor a la correspondiente al testigo. 
TABLA 2. Resultados electroquímicos para los diferentes materiales ensayados

\begin{tabular}{|c|c|c|c|c|c|}
\hline Material & $\begin{array}{c}\mathbf{E}_{\text {corr }} \\
(\mathrm{V})\end{array}$ & 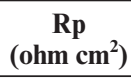 & $\begin{array}{c}\text { ba } \\
\left(\mathrm{V} \mathrm{dec}^{-1}\right)\end{array}$ & $\begin{array}{c}\text { bc } \\
\left.(\mathrm{V} \mathrm{dec})^{-1}\right) \\
\end{array}$ & $\begin{array}{c}i_{\text {corr }} \\
\left(\mathrm{A} \mathrm{cm}^{-2}\right) \times 10^{-5}\end{array}$ \\
\hline \multirow{2}{*}{ AT } & $-0,138$ & 1780 & 0,218 & $-0,108$ & 2,0 \\
\hline & $-0,209$ & 3820 & 0,128 & $-0,232$ & 0,9 \\
\hline \multirow{2}{*}{$\begin{array}{l}\text { AISI } \\
316\end{array}$} & $-0,206$ & 17250 & 0,192 & $-0,127$ & 0,2 \\
\hline & $-0,376$ & 13500 & 1,26 & $-0,220$ & 0,6 \\
\hline \multirow{2}{*}{ AL } & $-0,116$ & 2180 & 0,128 & $-0,108$ & 1,0 \\
\hline & $-0,194$ & 1390 & 0,258 & $-0,344$ & 5,0 \\
\hline
\end{tabular}

Los diagramas de Nyquist y Bode obtenidos en los ensayos EIS se muestran en las Figuras 7, 8 y 9. Las respuestas de EIS de AISI 316 y AT sin exponer muestran dos constantes de tiempo. Por tanto, se decide realizar el ajuste en dichos diagramas según el modelo de la Figura 4. Este modelo incluye un proceso difusivo en geometría finita, una resistencia a la transferencia de carga que puede ser asociada tanto a las reacciones catódicas (reducción de oxígeno y/o evolución de hidrógeno) como anódicas (electrooxidación de los metales presentes en la aleación) y un elemento CPE para modelar la doble capa electroquímica de la interfase.

Para las tres probetas expuestas y la probeta de AL testigo, los diagramas presentan aparentemente una única constante de tiempo. Por tanto, se les ajusta el modelo de la Figura 5, el cual no contiene el elemento difusivo incluido en el modelo de la Figura 4.

Los resultados del ajuste de los modelos propuestos se presentan en la Tabla 3. La correspondiente bondad de ajuste del resultado se expresa a través del valor $\chi^{2}$ (a mayor valor de $\chi^{2}$, menos verosímil es el ajuste) (Ec. 4):

$$
\chi^{2}=\sum_{i} \frac{\left(\chi_{\text {ajuste }_{i}}-\chi_{\text {experimental }_{i}}\right)^{2}}{\chi_{\text {experimental }}}
$$

El efecto difusivo en AISI 316 y AT (sin exponer) podría deberse a la formación de una película fina de productos de corrosión sobre la superficie de los testigos durante los ensayos EIS. Los parámetros relacionados con el elemento Warburg presentan alta incertidumbre en el ajuste. Los valores del ajuste correspondientes al parámetro WsT, son del orden de $10^{-17}$ o $10^{-20} \mathrm{~s}$. Considerando una difusividad en medio sólido de $10^{-8} \mathrm{~cm}^{2} \mathrm{~s}^{-1}$ (Armstrong, 1986), estos valores se asociarían a un espesor de película (calculado según la ecuación 2) de $10^{-13}$ y $10^{-14} \mathrm{~cm}$, para AT y AISI 316 respectivamente. Sin embargo, como WsP ajusta a valores inferiores a 0,5 , el significado físico de WsT puede no estar reflejado estrictamente por la ecuación (2) (Lasia, 1999).
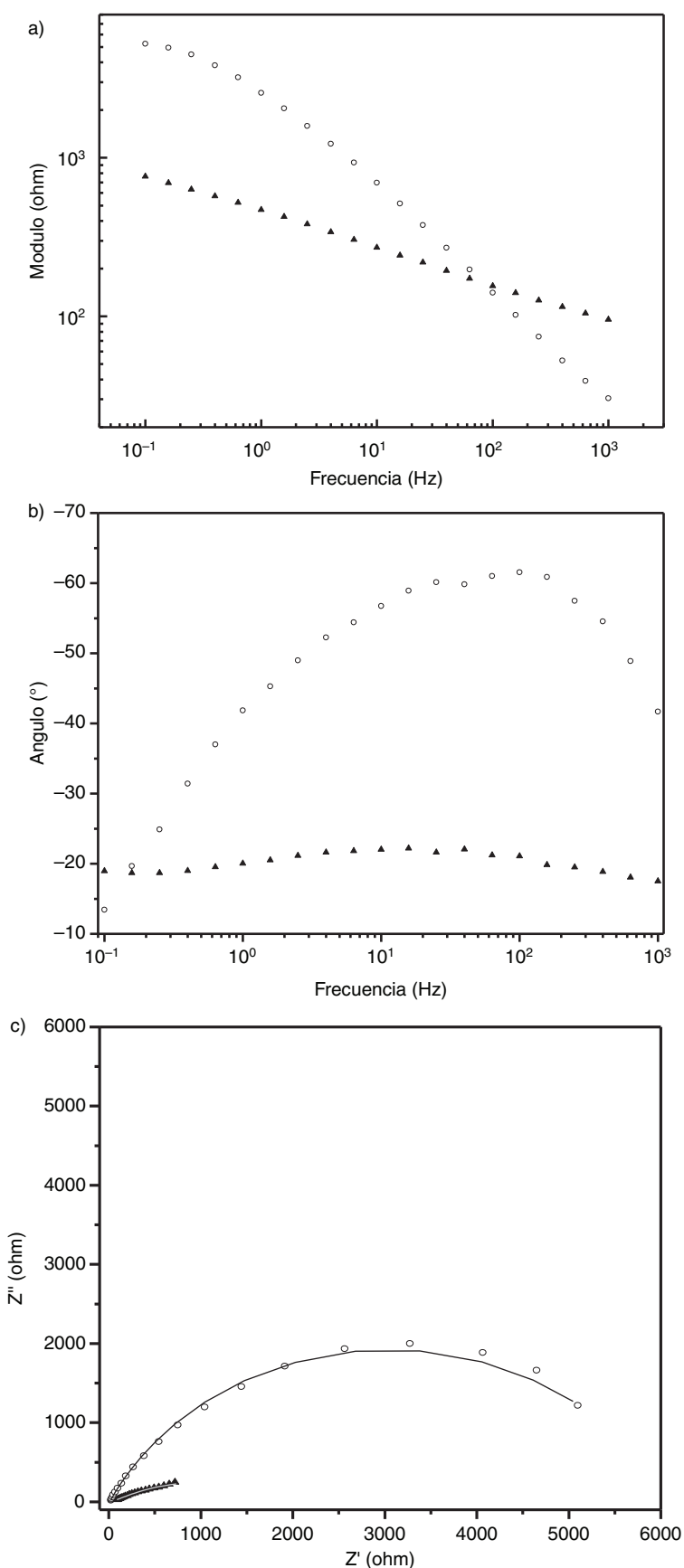

Figura 7. Diagramas de: a) Bode módulo; b) Bode fase y c) Nyquist para latón aluminio UNS C68700 (AL). Probeta testigo en círculos blancos, probeta expuesta en triángulos negros. En el diagrama Nyquist se presentan datos de ajuste (trazo negro probeta testigo, trazo gris probeta expuesta).

Los valores correspondientes a $Y_{1}$ para las muestras sin exponer se encuentran en el rango habitual de valores de doble capa electroquímica (Polo y Bastidas, 2000). Los valores para la muestra expuesta de AT aumentan en un orden de magnitud respecto a la muestra testigo. Los otros metales 

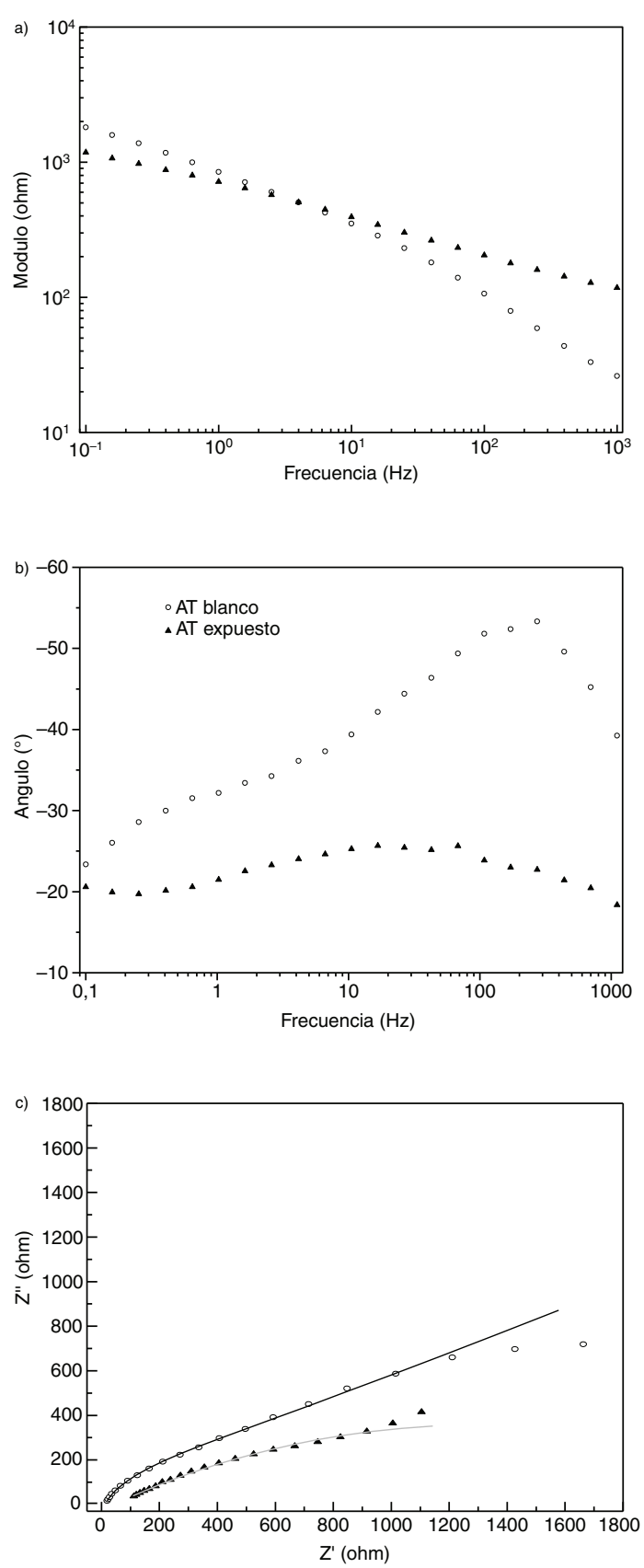

Figura 8. Diagramas de: a) Bode módulo; b) Bode fase y c) Nyquist para latón almirantazgo UNS C443 (AT).

Probeta testigo en círculos blancos, probeta expuesta en triángulos negros. En el diagrama de Nyquist se presentan datos de ajuste (trazo negro probeta testigo, trazo gris probeta expuesta).

presentan una ligera disminución de la capacidad después de ser expuestos. El parámetro $\alpha$ es un factor que corrige heterogeneidades en la capacidad de la doble capa: valores cercanos a la unidad implican una capa homogénea y un comportamiento completamente capacitivo (Kosec et al., 2008). Este
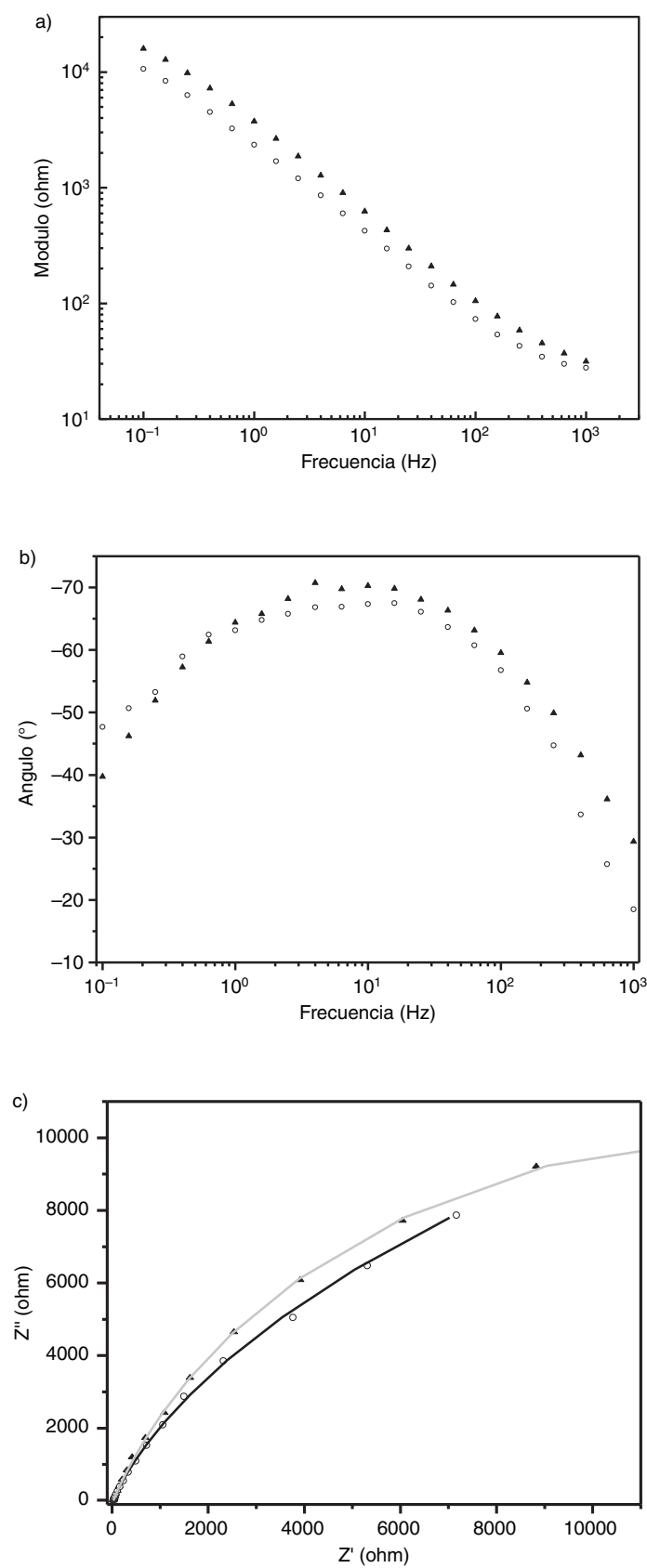

Figura 9. Diagramas de: a) Bode módulo; b) Bode fase y c) Nyquist para acero inoxidable AISI 316 (AISI 316). Probeta testigo en círculos blancos, probeta expuesta en triángulos negros. En el diagrama de Nyquist se presentan datos de ajuste (trazo negro probeta testigo, trazo gris probeta expuesta).

parámetro, en los ensayos de muestra sin exponer y en AISI 316 expuesto, ajusta a valores cercanos a 0,8 . Sin embargo, para el caso de AL y AT expuestos, el valor del ajuste del parámetro $\alpha$ es cercano a 0,3 lo que implica alta heterogeneidad en el comportamiento capacitivo (ya sea por heterogeneidad 
TABla 3. Ajuste de parámetros EIS, para modelos de Figuras 4 y 5. AT: latón almirantazgo UNS C443, 316: acero inoxidable AISI 316, AL: latón aluminio UNS C68700

\begin{tabular}{|c|c|c|c|c|c|c|c|c|}
\hline Material & $\chi^{2} \times 10^{-3}$ & $\begin{array}{c}\mathrm{Rs} \\
\left(\Omega \mathrm{cm}^{2}\right)\end{array}$ & $\begin{array}{c}R_{1} \\
\left(\Omega \mathrm{cm}^{2}\right)\end{array}$ & $\left(\mathrm{Fcm}^{-2} \mathrm{~s}^{-(1-\alpha)}\right) \times 10^{-4}$ & $\alpha$ & $\begin{array}{c}\text { WsR } \\
\left(\Omega \mathrm{s}^{-1 / 2}\right) \times 10^{-3}\end{array}$ & $\begin{array}{l}\text { WsT } \\
(\mathbf{s})\end{array}$ & WsP \\
\hline AT testigo & 1 & 13 & 200 & 0,50 & 0,79 & 5 & $1 \times 10^{-17}$ & 0,16 \\
\hline $\begin{array}{l}\text { AT } 15 \text { días } \\
\text { de exposición }\end{array}$ & 0,8 & 43 & 2500 & 6,0 & 0,35 & - & - & - \\
\hline AISI 316 testigo & 0,8 & 23,0 & 200 & 0,8 & 0,82 & 8 & $1 \times 10^{-20}$ & 0,13 \\
\hline $\begin{array}{l}\text { AISI } 31615 \text { días } \\
\text { de exposición }\end{array}$ & 0,5 & 23,0 & 27500 & 0,58 & 0,80 & - & - & - \\
\hline AL testigo & 3,0 & 10,7 & 6100 & 0,73 & 0,72 & - & - & - \\
\hline $\begin{array}{l}\text { AL } 15 \text { días } \\
\text { de exposición }\end{array}$ & 2,0 & 34 & 2100 & 0,11 & 0,31 & - & - & - \\
\hline
\end{tabular}

en el espesor como por heterogeneidad en el valor del dieléctrico). Otra interpretación a estos valores de $\alpha$, es que esté presente otra constante de tiempo, la cual no es posible dilucidar a partir de los espectros. Por tanto el elemento de fase constante puede responder tanto al comportamiento capacitivo de la doble capa electroquímica como a la existencia de un fenómeno difusivo.

En el ajuste presentado en la Tabla 3, se puede observar que los valores de las resistencias a la transferencia de carga $\mathrm{R}_{1}$ aumentan en las probetas expuestas AT y AISI 316, mientras que disminuye en AL. El comportamiento de Rp de AT y AL sigue la misma tendencia (ver Tabla 2), no así en el caso de AISI 316 ( $\mathrm{R}_{1}$ aumenta mientras $\mathrm{Rp}$ disminuye). Sin embargo, debe tenerse en cuenta que el ajuste de AISI 316 expuesto considera un elemento difusivo, que afecta la determinación de $\mathrm{Rp}$. Igual consideración se puede hacer para AT: $R_{1}$ aumenta un orden de magnitud mientras que $\mathrm{Rp}$ se duplica en la probeta expuesta.

El potencial de corrosión disminuye en las superficies expuestas, lo cual está en desacuerdo con los resultados obtenidos por Oya San et al., (2012), que indican que la superficie adquiere un carácter más noble. El ennoblecimiento sería acorde con un comportamiento de capa pasiva que dificulta el fenómeno de transporte de reactivos y productos a la interfase electroquímica. Otros autores (Starosvetsky et al., 2008) indican que la disminución del potencial de corrosión, es debida a un debilitamiento de la capa pasiva, a una activación de la superficie o a la disminución de la concentración de oxígeno disuelto. Las condiciones en la bio-película pueden cambiar la preponderancia de las posibles reacciones asociadas, en particular la generación de condiciones ácidas y la disminución del aporte de oxígeno harían relevante la evolución de hidrógeno. Todo ello se coincide con un aumento en valor absoluto de la pendiente de Tafel catódica. Por otra parte, las respuestas EIS no respaldan en forma concluyente la hipótesis de control difusional.
En los casos estudiados, la disminución del potencial de corrosión, se asociaría a una menor tendencia a la localización del ataque. En el caso del comportamiento de AISI 316, existe un desacuerdo entre la existencia de alta inestabilidad de las medidas en los potenciales cercanos al de corrosión y la disminución del potencial de corrosión. Si existe un cambio del mecanismo preponderante de reacción catódica (de reducción de oxígeno a evolución de hidrógeno), la contradicción no sería tal y la inestabilidad sería generada por la nucleación de hidrógeno.

La influencia específica de las BSR sobre la corrosión de materiales ferrosos (como por ejemplo Desulfovibrio desulfuricans) está descrita en la bibliografía (Javaherdashti, 2008). Las BSR obtienen su energía de nutrientes orgánicos y son estrictamente anaerobias, por lo tanto no requieren de oxígeno para su crecimiento y actividad. Usan el sulfato como receptor externo de electrones en lugar del oxígeno, con la consecuente producción de sulfuro. El mecanismo de acción de las BSR propuesto por Stott et al., (1988) se denomina despolarización catódica, usando el hidrógeno producido catódicamente para transformar sulfato en sulfuro mediante la enzima deshidrogenasa. Otro mecanismo propuesto atribuye el aumento de la MIC por BSR al efecto de la despolarización por hidrogenasa sumado a la formación de micropares galvánicos metalsulfuro de metal (Stott, 1993). Sin embargo Little y Wagner (1997) relativizan la influencia del crecimiento de las BSR sobre la velocidad de corrosión (Javaherdashti, 2008). Aunque el mayor crecimiento de dicho grupo de bacterias se desarrolla sobre el AISI 316, su velocidad media de corrosión es inferior a los otros metales expuestos, pero mayor al material sin exponer. Sin embargo, se debe resaltar el posible aumento de la tendencia a la localización, que en el caso de la aplicación considerada (tubos de intercambio de calor) puede generar picaduras con consiguiente paro de la unidad y obturación del tubo correspondiente (Ohanian, 2011). 


\section{CONCLUSIONES}

En las condiciones del presente trabajo, se observa una influencia del material sobre el crecimiento de la bio-película. Este efecto se observa especialmente sobre las BSR, uno de los principales grupos de microorganismos asociados a la biocorrosión de metales. Aunque el acero inoxidable AISI 316 posee una velocidad media de corrosión inferior a los otros materiales ensayados, presenta una tendencia a la generación de fenómenos de deterioro localizado. Los latones presentan una mayor velocidad media de corrosión, lo cual lejos de ser un perjuicio, puede constituir una superioridad frente al acero inoxidable, ya que la disolución del cobre podría ser responsable de la inhibición del crecimiento de BSR.

\section{REFERENCIAS}

Armstrong, R.D. (1986). Impedance plane display for an electrode with diffusion restricted to a thin layer. J. Electroanal. Chem. 198 (1), 177-180. http://dx.doi.org/ 10.1016/0022-0728(86)90034-3.

ASTM Standard G3-13 (2013). Standard Practice for Conventions Applicable to Electrochemical Measurements in Corrosion Testing. ASTM International, Philadelphia, 2013.

Cottis, R.A. (2010). Electrochemical Methods, en: Cottis, R.A., Graham, M.J., Lindsay, R., Lyon, S.B., Richardson, J.A., Scantlebury, J.D., Stott, H. (Eds). Shreir's Corrosion. Elsevier B.V., Amsterdam, pp. 1341-1373.

Cristiani, P. (2005). Solutions to fouling in power station condensers. Appl. Therm. Eng. 25 (16), 2630-2640. http:// dx.doi.org/10.1016/j.applthermaleng.2004.11.029.

de Romero, M.F., Duque, Z., de Rincón, O.T., Pérez, O. Araujo, I. (2003). Estudio de la teoría de despolarización catódica con permeación de hidrógeno y la bacteria Desulfovibrio desulfuricans. Rev. Metal. 39 (Extra), 182-187. http://dx.doi. org/10.3989/revmetalm.2003.v39.iExtra.1117.

Faires, V.M., Simmang, C.M. (1982). Termodinámica. Ed. UTEHA., 6 a Edición, México, pp. 234-261.

Gómez de Saravia, S.G., Guiamet, P.S., Videla, H.A. (2003). Prevención y protección de los efectos de la biocorrosión y el biofouling con mínimo impacto ambiental. Rev. Metal. 39 (Extra), 49-54. http://dx.doi.org/10.3989/revmetalm. 2003.v39.iExtra.1096.

IMM Servicio Laboratorio de Calidad Ambiental, (2011). Estudio de la calidad de agua, sedimento y biota del Río de la Plata. Evaluación de línea de base. Informe Anual -2011

Javaherdashti, R. (2008). Microbiologically Influenced Corrosion: An Engineering Insight. Springer-Verlag, London, pp. 29-66.

Kosec, T., Merl, D.K. Milosev, I. (2008). Impedance and XPS study of benzotriazole films formed on copper, copperzinc alloys and zinc in chloride solution. Corros. Sci. 50 (7), 1987-1997. http://dx.doi.org/10.1016/j.corsci.2008.04.016.

Lasia, A. (1999). Electrochemical Impedance Spectroscopy and Its Applications, Modern Aspects of Electrochemistry, Vol. 32, Conway, B.E., Bockris, J., White, R. (Eds). Kluwer Academic/Plenum Publishers, New York, pp. 143-248.
Little, B.J., Lee, J.S. (2007). Microbiologically Influenced Corrosion. Wiley-Interscience, Hoboken, New Jersey, USA, pp. 1-22.

Little, B. J., Wagner P. (1997). Myths Related to microbiologically Influenced Corrosion. Mater. Performance 36 (6), pp. $40-44$.

Liu, H., Xu, L. Zeng, J. (2000). Role of corrosion products in biofilms in microbiologically induced corrosion of carbon steel. Brit. Corros. J. 35 (2), 131-135. http://dx.doi.org/ $10.1179 / 000705900101501155$.

Ohanian, M., Díaz, V., Corengia, M., Zinola, C.F. (2011). Estudio de corrosión galvánica en pares latón/acero inoxidable y latón/fundición de hierro. Rev. Metal. 47 (4), 319-328. http://dx.doi.org/10.3989/revmetalm.1047.

Orazem, M.E., Tribollet, B. (2008a). Electrochemical Impedance Spectroscopy, John Wiley \& Sons, Hoboken, New Jersey, USA, pp. 61-72.

Orazem, M.E., Tribollet, B. (2008b). Electrochemical Impedance Spectroscopy, John Wiley \& Sons, Hoboken, New Jersey, USA, pp. 183-210.

Oya San, N., Nazir, H., Dönmez, G. (2012). Evaluation of microbiologically influenced corrosion inhibition on Ni-Co alloy coatings by Aeromonas salmonicida and Clavibacter michiganensis. Corros. Sci. 65, 113-118. http://dx.doi.org/ 10.1016/j.corsci.2012.08.009.

Polo, J.L., Bastidas, J.M. (2000). Líneas de transmisión: su utilización en la interpretación de las medidas de impedancia en los estudios de corrosión. Rev. Metal. 36, 357-365. http://dx.doi.org/10.3989/revmetalm.2000.v36.i5.586.

Roberge, P.R. (1999). Handbook of Corrosion Engineering. McGraw Hill, New York, USA, pp. 1072-1074.

Russi, P., Pianzzola, M.J., Menes, J., Corengia, M., Diaz, V., Ohanian, M. (2012). Influencia microbiológica sobre la corrosión: ensayos sobre materiales de interés tecnológico realizados en la Bahía de Montevideo. V Encuentro Regional y XXVI Congreso Interamericano de Ing. Química, Montevideo, Uruguay.

Starosvetsky, J., Starosvetsky, D., Pakroy, B., Hilel, T., Armon, R. (2008). Electrochemical behaviour of stainless steels in media containing iron-oxidizing bacteria (IOB) by corrosion process modeling. Corros. Sci. 50 (2), 540-547. http:// dx.doi.org/10.1016/j.corsci.2007.07.008.

Stott, J.F.D. (1993). What progress in the understanding of microbially induced corrosion has been made in the last 25 years? A personal viewpoint. Corros. Sci. 35 (1-4), 667-673. http://dx.doi.org/10.1016/0010-938X(93)90202-R.

Stott, J.F.D. (2010). Corrosion in Microbial Environments, en: Cottis, R.A., Graham, M.J., Lindsay, R., Lyon, S.B., Richardson, J.A., Scantlebury, J.D., Stott, H. (Eds). Shreir's Corrosion. Elsevier B.V., Amsterdam, pp. 1169-1190.

Stott J., Skerry B., King R. (1988). Laboratory Evaluation of Materials for Resistance to Anaerobic Corrosion by SulfateReducing Bacteria: Philosophy and Practical Design, en Francis, P.E, Lee, T.S. (Eds.). The Use of Synthetic Environments for Corrosion Testing, ASTM STP 970, American Society for Testing and Materials, Philadelphia, pp. 98-111.

Tanner, R.S. (1989). Monitoring sulfate-reducing bacteria: comparison of enumeration media. J. Microbiol. Methods 10 (2), 83-90. http://dx.doi.org/10.1016/0167-7012(89)90004-3.

Videla, H.A. (1996). Manual of Biocorrosion, CRC Press, Boca Raton, FL, p. 241.

Videla, H.A., Salvarezza, R.C. (1984). Introducción a la Corrosión Microbiológica. Librería Agropecuaria, Buenos Aires, p. 83. 